\title{
Relative expression of proprotein convertases in rat ovaries during pregnancy
}

\author{
Simon CM Kwok ${ }^{1 *}$, Damayanti Chakraborty ${ }^{2}$, Michael J Soares ${ }^{2}$ and Guoli Dai ${ }^{3}$
}

\begin{abstract}
Background: Proprotein convertases are a family of serine proteinases that are related to bacterial subtilisin and yeast kexin. They are involved in posttranslational processing of the precursors of a vast number of cellular proteins. With the exception of $\mathrm{PC} 1 / 3$, the relative expression levels of the proprotein convertases in the ovary during pregnancy have not been reported. The purpose of this study is to determine by real-time PCR the relative expression levels of all nine proprotein convertases in rat ovaries during pregnancy and at 3 days postpartum.

Methods: RNA was extracted from ovaries at Day $0,4,9,11,13,15,18$, and 20 of pregnancy as well as 3 days postpartum. Relative expression levels of Pcsk1, Pcsk2, Furin, Pcsk4, Pcsk5, Pcsk6, Pcsk7, Mbtps1 and Pcsk9 were determined with real-time PCR. Results were reported as fold-change over the level at Day 0 of pregnancy.

Results: Results showed that Pcsk1 and Pcsk6 were upregulated as gestation advanced, in parallel with an observed increase in relaxin transcript. Pcsk2 showed downregulation as gestation advanced, while Pcsk5 showed relatively higher levels in early pregnancy and postpartum, but lower level in mid-pregnancy. On the other hand, Furin, Pcsk4, Pcsk7, Mbtps1 and Pcsk9 showed little change of expression throughout gestation.
\end{abstract}

Conclusion: PC1/3 (PCSK1) and PACE4 (PCSK6) may play an important role in proprotein processing in the ovary during late pregnancy.

Keywords: Prohormone convertase, Gene expression, Posttranslational processing

\section{Background}

Proprotein convertases are a family of serine proteinases that are related to bacterial subtilisin and yeast kexin. They are involved in posttranslational processing of a vast number of cellular proteins leading to their activation and sometimes inactivation. There are nine members identified so far: they are PC1/3, PC2, Furin, PC4, PC5/6, PACE4, PC7, SKI-1/S1P, and PCSK9 (NARC-1) [1]. Their genes are named Pcsk1, Pcsk2, Furin, Pcsk4, Pcsk5, Pcsk6, Pcsk7, Mbtps1, and Pcsk9. The first seven members process precursor proteins at single or paired basic amino acids with the motif of $(\mathrm{R} / \mathrm{K}) \mathrm{X}_{\mathrm{n}}(\mathrm{R} / \mathrm{K}) \downarrow$ (where $\mathrm{R}=$ arginine, $\mathrm{K}=$ lysine, $\mathrm{X}=$ any amino acid). They share a cleavage redundancy towards numerous substrates, such as protein hormones, receptors, adhesion molecules and metalloproteinases. The eighth member, SKI-1/S1P, cleaves membrane-bound

\footnotetext{
* Correspondence: kwokscm@hotmail.com

'ORTD, Albert Einstein Medical Center, 5501 Old York Road, Philadelphia, PA 19141-3098, USA

Full list of author information is available at the end of the article
}

transcription factors and $\mathrm{N}$-acetylglucosamine-1-phosphotransferase at the motif of $\mathrm{RX}(\mathrm{L} / \mathrm{V} / \mathrm{I}) \mathrm{X} \downarrow$ (where $\mathrm{L}=$ leucine, $\mathrm{V}=$ valine, $\mathrm{I}=$ isoleucine), and the last member, PCSK9, cleaves itself at $\mathrm{VFAQ}^{152} \downarrow$ (valine-phenylalanine-alanineglutamine ${ }^{152}$ ) sequence [2].

Of these nine proprotein convertases, Furin, PC5/6, PACE4, PC7, and SKI-1/S1P are ubiquitously expressed [3-7]. Expression of $\mathrm{PC} 1 / 3$ and $\mathrm{PC} 2$ is restricted to neuroendocrine tissues [8]. PC4 is expressed primarily in male germ cells, although it is also expressed in ovary and placenta [9]. PCSK9 (NARC-1) is expressed in adult liver, small intestine and kidney [10]. These proprotein convertases have been implicated to play an important role in follicle development and ovulation. PC5/6 was upregulated in rat ovarian follicles by gonadotropins and may be involved in the processing of precursors of transforming growth factor beta (TGF $\beta$ ) and matrix metalloproteinases [11]. Both PC5/6 and inhibin were upregulated during follicle development in mouse ovary, suggesting that PC5/6 may be involved in inhibin subunit processing [12]. 
PACE4 (PCSK6) expression in preantral granulosa cells was upregulated by follicle-stimulating hormone (FSH), but was suppressed by factors secreted by full-grown oocytes from antral follicles [13]. The change of PACE4 expression may suggest a change of mechanism involved in the processing of the precursors of the TGF $\beta$ family. Using Pcsk6-knockout mice, Mujoomdar and co-workers [14] showed that PACE4 played an important role in maintaining normal cellular and tissue homeostasis in the ovary. Expression of Pcsk6 in human granulosa cells and oocytes was suppressed by bone morphogenetic proteins, suggesting that it was subjected to bone morphogenetic protein negative feedback [15]. Furin was upregulated in rat ovary treated with gonadotropin, whereas both matrix metalloproteinase 2 (MMP2) activation and oocyte release were decreased after treatment with furin inhibitor [16]. These results suggest a role of furin in the breakdown of follicular wall during ovulation. Furin may also be involved in proliferation of granulosa cells, since knockdown of furin expression with furin siRNA decreased proliferation of granulosa cells [17]. Expression of these proprotein convertases in the ovary during gestation has not been well studied. Our laboratory has cloned and characterized multiple $\mathrm{PC} 1 / 3$ transcripts from porcine ovary [18]. In situ hybridization showed that $\mathrm{PC} 1 / 3$ and relaxin transcripts were colocalized in large luteal cells of porcine ovary and levels of both transcripts increased as gestation advanced [19]. This suggests that PC1/3 may be involved in posttranslational processing of prorelaxin. The purpose of the present study is to investigate the relative expression levels of all nine proprotein convertases in rat ovaries during gestation using real-time PCR.

\section{Methods}

\section{Animals and tissue preparation}

Holtzman Sprague-Dawley rats were obtained from Harlan Laboratories (Indianapolis, IN). The animals were housed in an environmentally controlled facility with lights on from 0600 to $2000 \mathrm{hr}$ and allowed free access to food and water. Timed pregnancies were obtained by housing female rats with male rats and examining vaginal smears daily during the cohabitation. The presence of a copulatory plug or sperm in the vaginal smear was designated Day 0 of pregnancy. Rats were sacrificed on Day 0, $4,9,11,13,15,18,20$ of pregnancy as well as 3 days postpartum, and ovaries were quickly removed, frozen with liquid nitrogen and stored in $-80^{\circ} \mathrm{C}$ freezer. Ovaries were collected from 3-4 rats for each time point. The University of Kansas Animal Care and Use Committee approved protocols for the care and use of rats used in the experiments.

\section{Regular RT-PCR}

Total RNA was extracted from individual ovaries using NucleoSpin ${ }^{\bullet}$ RNA L Kit (Clontech, Palo Alto, CA), with the aide of an Omni Tissue Homogenizer. First-strand cDNA was synthesized from $5 \mu \mathrm{g}$ of total RNA using ThermoScript (Life Technologies, Carlsbad, CA) in a volume of $40 \mu \mathrm{l}$. PCR was done for 30 cycles (denaturation at $94^{\circ} \mathrm{C}$ for $30 \mathrm{sec}$, annealing at $59^{\circ} \mathrm{C}$ for $30 \mathrm{sec}$, and extension at $72^{\circ} \mathrm{C}$ for $60 \mathrm{sec}$ ) using $1 \mu \mathrm{l}$ of the first-strand cDNA, 10 pmol of gene specific primers (Table 1) and 2.5 units of JumpStart Taq DNA polymerase (Sigma-Aldrich, St. Louis, MO) in $50 \mu \mathrm{l}$ of $1 \mathrm{X}$ buffer containing $1.5 \mathrm{mM}$ $\mathrm{MgCl}_{2}$ and $200 \mu \mathrm{M}$ dNTP. Aliquots of $18 \mu \mathrm{l} \mathrm{PCR} \mathrm{prod-}$ ucts were analyzed on $2 \%$ agarose gels.

\section{Real-time PCR}

For real-time PCR, cDNA was synthesized from $2 \mu \mathrm{g}$ of total RNA, using High-Capacity cDNA Reverse Transcription Kit (Life Technologies, Carlsbad, CA). The resulting cDNA was diluted 1:10 with $10 \mathrm{mM}$ Tris $\mathrm{HCl}, \mathrm{pH}$ 8.0. Real-time PCR was performed with StepOne ${ }^{\text {tw }}$ real-time PCR system using the default protocol (Applied Biosystems, Foster City, CA). Each reaction was composed of $10 \mu \mathrm{l}$ of $2 \mathrm{X}$ TaqMan Gene Expression Master Mix, $1 \mu \mathrm{l}$ of ready-made Gene Expression Assay (Table 2; Applied Biosystems, Foster City, CA), $7 \mu \mathrm{l}$ of water and $2 \mu \mathrm{l}$ of diluted cDNA. Reactions were done in triplicate, and the $C_{T}$ values were used to calculate "fold-induction" over Day 0

Table 1 Primers for regular PCR

\begin{tabular}{|c|c|}
\hline Gene & Primers \\
\hline \multirow[t]{2}{*}{ Pcsk1 } & 5'-TATGACCCATTGGCCAATAACC-3' \\
\hline & 5'-TTCCCTTTCAGCCAACAGTACG-3' \\
\hline \multirow[t]{2}{*}{ Pcsk2 } & 5'-CGAAACCAGCTTCACGATGAG-3' \\
\hline & 5'-ACGCCGGCTTAGCAAAATGGA-3' \\
\hline \multirow[t]{2}{*}{ Furin } & 5'-CTATGGCTACGGGCTGTTGG-3' \\
\hline & 5'-CCTCGCTGGTATTITCAATCTC-3' \\
\hline \multirow[t]{2}{*}{ Pcsk4 } & 5'-CTTGTGGCCATCAGACCCTTG-3' \\
\hline & 5'-GAACAGGCAGTGTAGTCGCTG-3' \\
\hline \multirow[t]{2}{*}{ Pcsk5 } & 5'-AGTGCGCTCCATCTACAAAGC-3' \\
\hline & 5'-GTCAGTGCAGTGATCCGGTC-3' \\
\hline \multirow[t]{2}{*}{ Pcsk6 } & 5'-TATGGATTTGGCTTGGTGGATG-3' \\
\hline & 5'-GGCTCCATTCTITCAACTTTCC-3' \\
\hline \multirow[t]{2}{*}{ Pcsk7 } & 5'-CATTGTCTTCACAGCCACTCAG-3' \\
\hline & 5'-CAGTCTGTAGACTCCTCTTGC-3' \\
\hline \multirow[t]{2}{*}{ Mbtps1 } & 5'-TAAACGAGCTGCTGTCTGTGTG-3' \\
\hline & 5'-GAGTAGCGATGAAGGTGGTTTC-3' \\
\hline \multirow[t]{2}{*}{ Pcsk9 } & 5'-GAACTTGGCGTCTCATCCTGG-3' \\
\hline & 5'-CATTGCTTCTCTGGCCCTGTC-3' \\
\hline \multirow[t]{2}{*}{ Actb } & 5'-GCCAACCGTGAAAAGATGACC-3' \\
\hline & 5'-CCAGACAGCACTGTGTTGGCA-3' \\
\hline \multirow[t]{2}{*}{$R \ln 1$} & $5^{\prime}-A G C C A G G A G G A G C C A G C T C-3^{\prime}$ \\
\hline & 5'-TCATGACTGAGCATCTGAGCCTAAG-3' \\
\hline
\end{tabular}


Table 2 TaqMan gene expression assays from Applied Biosystems

\begin{tabular}{ll}
\hline Gene & Catalog number and assay ID \\
\hline Pcsk1 & Cat.\#: 4331182, ID: Rn00567266_m1 \\
Pcsk2 & Cat.\#: 4331182, ID: Rn00562543_m1 \\
Furin & Cat.\#: 4331182, ID: Rn00570970_m1 \\
Pcsk4 & Cat.\#: 4331182, ID: Rn00592006_m1 \\
Pcsk5 & Cat.\#: 4351372, ID: Rn01450817_m1 \\
Pcsk6 & Cat.\#: 4331182, ID: Rn00564475_m1 \\
Pcsk7 & Cat.\#: 4331182, ID: Rn00570376_m1 \\
Mbtps1 & Cat.\#: 4331182, ID: Rn00585707_m1 \\
Pcsk9 & Cat.\#: 4331182, ID: Rn01416753_m1 \\
Actb & Cat.\#: 4331182, ID: Rn00667869_m1 \\
RIn1 & Cat.\#: 4331182, ID: Rn00566383_m1 \\
\hline
\end{tabular}

control using Comparative $\mathrm{C}_{\mathrm{T}}$ method. $\mathrm{ACTB}$ was used as the internal control gene.

\section{Data analysis}

Data points shown represent mean \pm standard error. Statistically significant differences between data points of two groups were determined by Student's t-test. By convention, a $P$ value of $<0.05$ was considered statistically significant.

\section{Results}

All nine proprotein convertases are expressed in rat ovaries at Day 0 and Day 18 of pregnancy as determined by RT-PCR (Figure 1), except Pcsk1 at Day 18 probably due to variation in ovarian sample. In general, the pattern of expression of the nine proprotein convertases in ovaries at Day 18 of pregnancy is similar to that of ovaries at Day 0 of pregnancy. Among the proprotein convertase genes, Pcsk5 and Mbtps1 are expressed at the highest expression level; Furin, Pcsk6, Pcsk7 and Pcsk9 at a moderate level; whereas Pcsk1 and Pcsk2 at the lowest level. With the exception of Pcsk4, all proprotein convertases produced

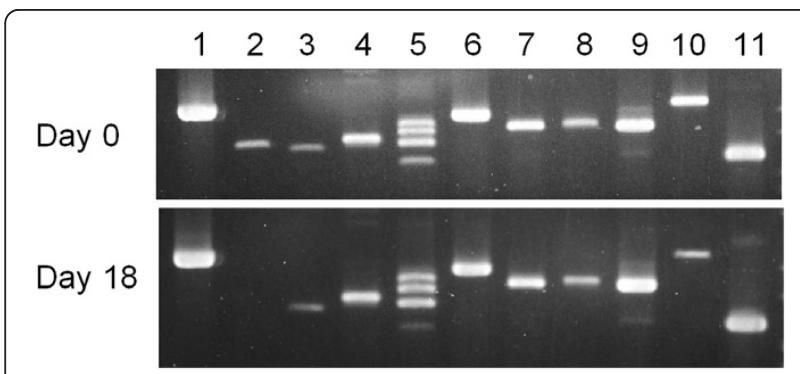

Figure 1 RT-PCR analyses of proprotein convertase expression in rat ovaries at Day 0 (top panel) and Day 18 (bottom panel) pregnancy using gene-specific primers (Table 1). PCR products were analyzed on $2 \%$ agarose gel and visualized by ethidium bromide staining. The genes are: Actb, Pcsk1, Pcsk2, Furin, Pcsk4, Pcsk5, Pcsk6, Pcsk7, Mbtps 1, Pcsk9 and RIn1 (lanes 1-11, respectively). single amplicons, which had been confirmed by cloning and nucleotide sequencing (data not shown). The reason for detecting multiple amplicons of Pcsk4 in ovarian cDNA is unknown, since only one amplicon is detected in testis cDNA using the same set of primers and is confirmed by nucleotide sequencing (data not shown). Redesign of another set of primers generated the same result. The identities of these multiple amplicons were not determined.

To determine the relative expression levels of these proprotein convertases at different stages of pregnancy, realtime PCR was used. Relative expression levels of the nine proprotein convertases throughout gestation and at 3 days postpartum are shown in Figures 2 and 3. Four patterns are observed: (1) Pcsk1 and Pcsk6 showed upregulation as gestation advanced; (2) Pcsk2 showed a downregulation trend, although the results were highly variable; (3) Pcsk5 showed relatively higher levels in early pregnancy and postpartum, but lower level in mid-pregnancy; (4) Furin, Pcsk4, Pcsk7, Mbtps1 and Pcsk9 showed little change of expression throughout gestation. As a positive control, the expression level of relaxin showed a steady increase as gestation progressed, followed by a precipitous drop at 3 days postpartum (Figure 4).

\section{Discussion}

In the present study, we have determined the relative expression levels of the nine proprotein convertase genes in rat ovaries throughout gestation. Of these nine proprotein convertase genes, only Pcsk1 and Pcsk6 were upregulated as gestation advanced, in parallel with the expression level of the relaxin gene. The others did not show a consistent pattern of change in the expression level. The results on the upregulation of Pcsk1 in rat ovaries during pregnancy agree with those of our previous study using porcine ovary [19]. So far, the relative levels of other proprotein convertases in ovaries during pregnancy have not been reported.

It is difficult to ascribe a specific substrate for each of the proprotein convertases, because of their complementary and redundant functions. Since the levels of Pcsk1 and Pcsk6 transcripts were greatly increased in late pregnancy, these enzymes may be involved in the posttranslational processing of prorelaxin, the precursor of the major peptide hormone of the ovary, relaxin, in late pregnancy. Judging from the relative intensities of Pcsk1 and Pcsk6 transcripts (Figure 1), PACE4 (PCSK6) may play a more important role in the posttranslational processing of prorelaxin. Although the relative level of Pcsk1 expression increased over 15-fold at Day 20 of pregnancy while that of Pcsk6 increased only 4-fold (Figures 2 and 3), Pcsk6 is expressed at a much higher basal level than Pcsk1 (Figure 1). Therefore, PCSK6 will be present at a much higher level in the ovary than PCSK1. Whether it plays a more important role than PCSK1 remains to be verified experimentally. It is 


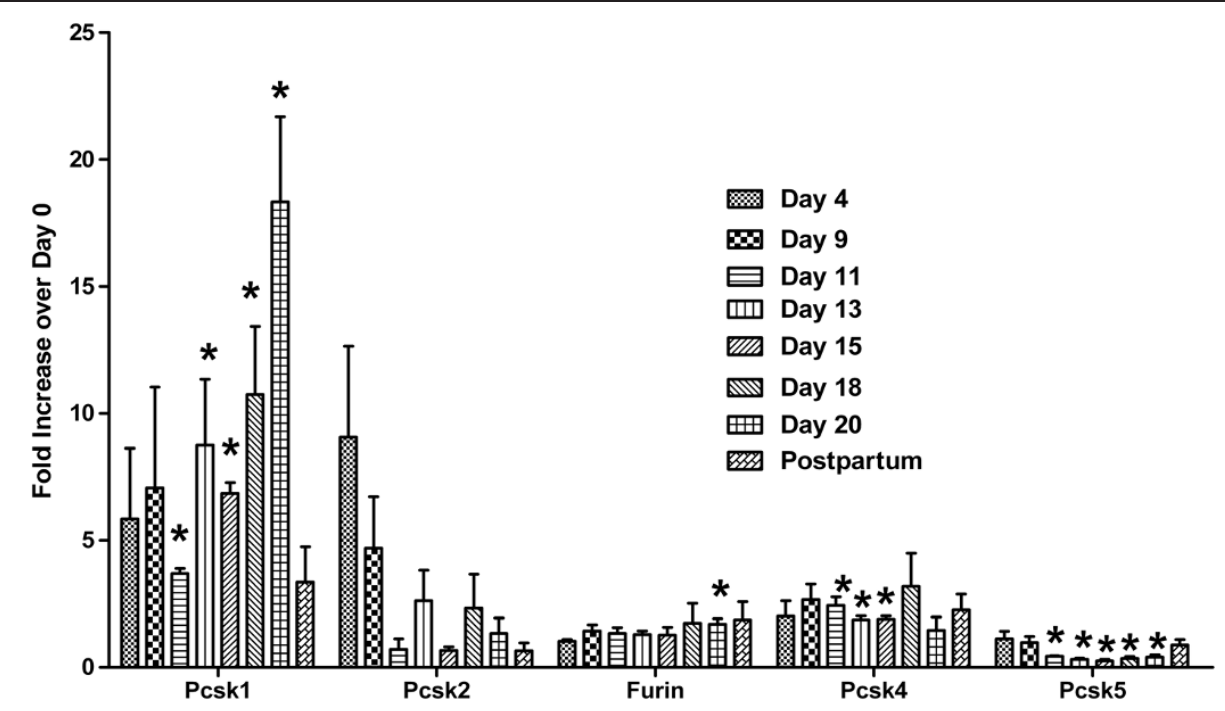

Figure 2 Relative expression levels of Pcsk1, Pcsk2, Furin, Pcsk4 and Pcsk5 in rat ovaries at Days 4, 9, 11, 13, 15, 18, and 20 of pregnancy, and 3 days postpartum. Relative proprotein convertase mRNA levels were determined by real-time PCR analyses as described in Methods. Results were expressed as "Fold Increase over Day 0 control" of the corresponding gene (mean \pm S.E.). $N=3$; ${ }^{*}<<0.05$ compared with Day 0 control.

of great interest to study the posttranslational processing of prorelaxin, since its expression level in the ovary gradually increases during the course of pregnancy. First, results from our laboratory and others showed that prorelaxin is biologically active [20-22]. Unlike the structurally similar proinsulin, proteolytic processing is not necessary for the biological activities of relaxin. Second, with the exception of human and primate prorelaxins [23-25], the paired basic residues required for recognition and cleavage by the first seven members of proprotein convertases are not present at the B-chain/C-peptide junction in prorelaxins of the other species. Processing of these prorelaxins at the Bchain/C-peptide junction will require other proteases. The B-chain/C-peptide junction of rat prorelaxin does not possess the recognition sequence of SKI-1/S1P and PCSK9.
Therefore, they are unlikely to be involved in the processing of prorelaxin. The identity of the proteases that process the prorelaxin at the B-chain/C-peptide junction remains to be studied. Third, the processing of prorelaxin is very slow, the majority of relaxin present in rat serum or ovary of late pregnancy were high molecular weight forms. On Day 20 pregnancy, only $25 \%$ of relaxin in rat serum was the $6 \mathrm{kDa}$ relaxin [26]. Two forms of high molecular weight (18 and $16.5 \mathrm{kDa}$ ) relaxin have also been detected in rat ovaries on Day 20 pregnancy and the combined concentration of these two forms was more than 30 times higher than that of $6 \mathrm{kDa}$ relaxin [27].

As mentioned in the introduction, PC5/6 may be involved in the processing of precursors of transformation growth factor and matrix metalloproteinase family [11],

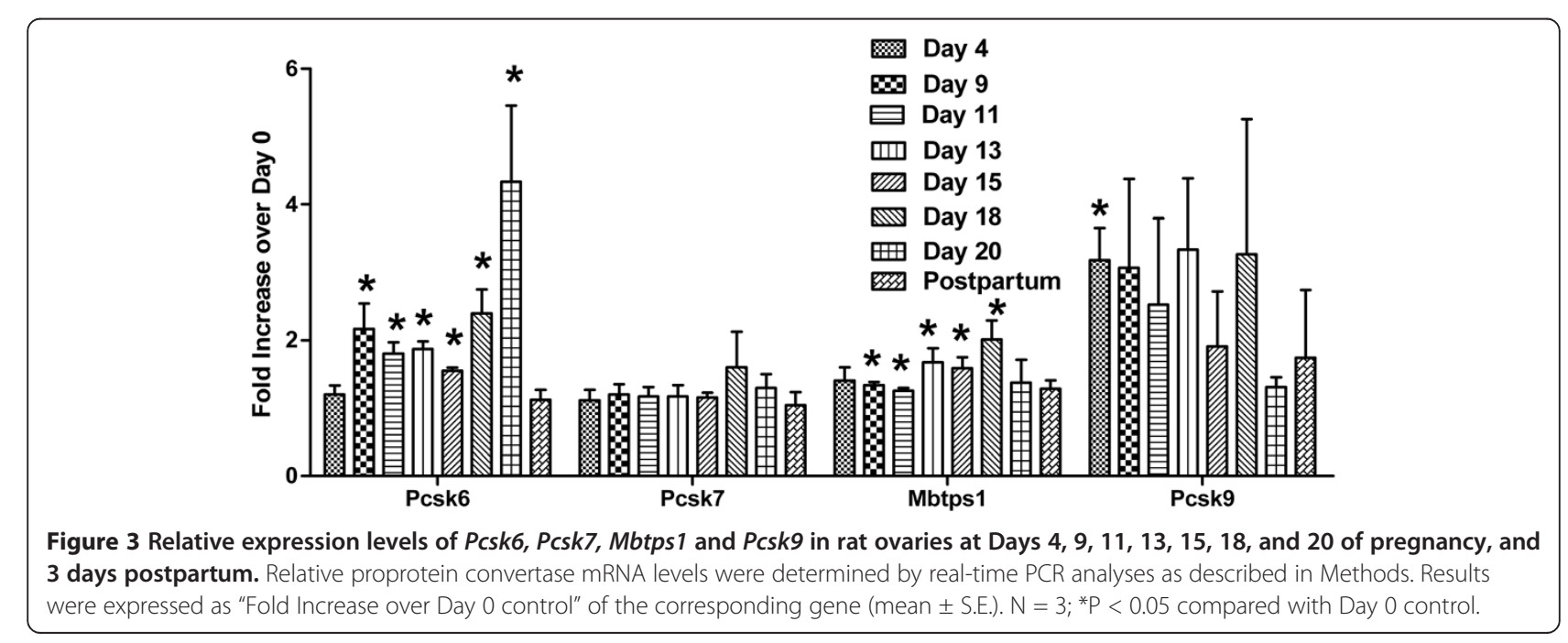




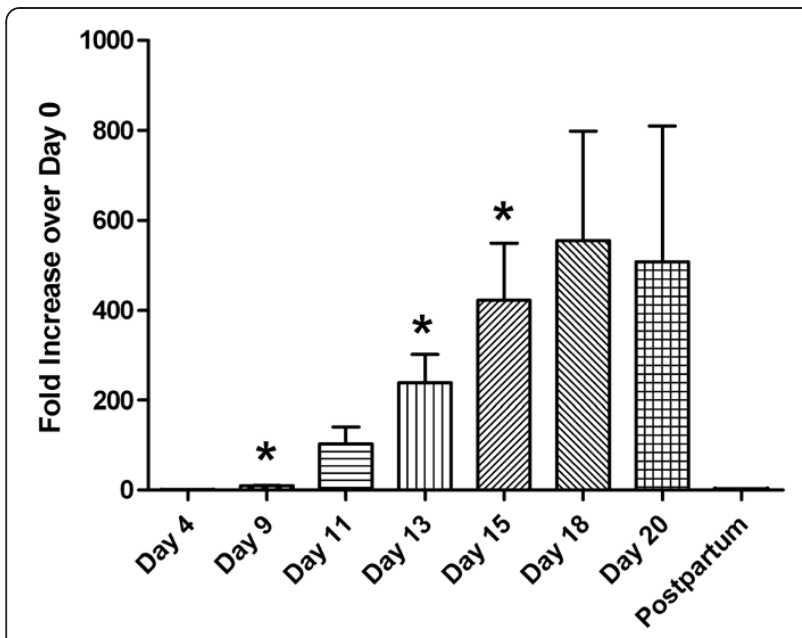

Figure 4 Relative expression levels of relaxin gene $(R \ln 1)$ in rat ovaries at Days 4, 9, 11, 13, 15, 18, and 20 of pregnancy, and 3 days postpartum. Relative relaxin mRNA levels were determined by real-time PCR analyses as described in Methods. Results were expressed as "Fold Increase over Day 0 control" of relaxin gene (mean \pm S.E.). $N=3$; ${ }^{*} \mathrm{P}<0.05$ compared with Day 0 control.

and that of inhibin [12]. On the other hand, furin may be involved in the processing of matrix metalloproteinase 2 [16]. PC4 is suggested to be the enzyme that processes pituitary adenylate cyclase-activating polypeptide [28].

\section{Conclusions}

In conclusion, all nine proprotein convertases are expressed in the rat ovary during gestation. Only $\mathrm{PC} 1 / 3$ and PACE4 were found to be upregulated as gestation advanced. They may play an important role in the processing of proproteins in the ovary during pregnancy. However, it is difficult to ascribe a specific substrate to these proprotein convertases.

\section{Abbreviations}

Actb: $\beta$-actin gene; Mbtps1: Membrane-bound transcription factor peptidase, site 1 gene; NARC-1: Neural apoptosis-regulated convertase-1; PACE4: Paired amino acid converting enzyme 4; PC: Proprotein convertase; PCR: Polymerase chain reaction; PCSK: Proprotein convertase subtilisin/kexin; RIn 1: Relaxin-1; S1P: Site-1 protease; siRNA: small interfering RNA; SKI-1: Subtilisin/kexin-like isozyme-1; TGF $\beta$ : Transforming growth factor beta.

\section{Competing interests}

The authors declare that they have no competing interests.

\section{Authors' contributions}

SK performed the experiments of molecular biology and wrote the manuscript. DC and MS designed and collect the rat ovaries needed for this study. GD helped to run a preliminary study. All authors read and approved the final manuscript.

\section{Acknowledgments}

This work was supported by a Grant from Albert Einstein Society to SCMK.

\section{Author details}

'ORTD, Albert Einstein Medical Center, 5501 Old York Road, Philadelphia, PA 19141-3098, USA. ${ }^{2}$ Institute for Reproductive Health and Regenerative Medicine, University of Kansas Medical Center, Kansas City, Kansas, USA. ${ }^{3}$ Department of Biology, Indiana University-Purdue University Indianapolis, Indianapolis, IN, USA.
Received: 18 October 2013 Accepted: 6 December 2013

Published: 11 December 2013

\section{References}

1. Seidah NG, Sadr MS, Chrétien M, Mbikay M: The multifaceted proprotein convertases: their unique, redundant, complementary, and opposite functions. J Biol Chem 2013, 288:21473-21481.

2. Seidah NG, Prat A: The biology and therapeutic targeting of the proprotein convertases. Nat Rev Drug Discov 2012, 11:367-383.

3. Hatsuzawa K, Hosaka M, Nakagawa T, Nagase M, Shoda A, Murakami K, Nakayama K: Structure and expression of mouse furin, a yeast Kex2-related protease. Lack of processing of coexpressed prorenin in GH4C1 cells. J Biol Chem 1990, 265:22075-22078.

4. Lusson J, Vieau D, Hamelin J, Day R, Chrétien M, Seidah NG: cDNA structure of the mouse and rat subtilisin/kexin-like PC5: a candidate proprotein convertase expressed in endocrine and nonendocrine cells. Proc Natl Acad Sci USA 1993, 90:6691-6695.

5. Tsuji A, Mori K, Hine C, Tamai Y, Nagamune H, Matsuda Y: The tissue distribution of mRNAs for the PACE4 isoforms, kexin-like processing protease: PACE4C and PACE4D mRNAs are major transcripts among PACE4 isoforms. Biochem Biophys Res Commun 1994, 202:1215-1221.

6. Seidah NG, Hamelin J, Mamarbachi M, Dong W, Tardos H, Mbikay M, Chretien M, Day R: CDNA structure, tissue distribution, and chromosomal localization of rat PC7, a novel mammalian proprotein convertase closest to yeast kexin-like proteinases. Proc Natl Acad Sci USA 1996, 93:3388-3393.

7. Seidah NG, Mowla SJ, Hamelin J, Mamarbachi AM, Benjannet S, Touré BB, Basak A, Munzer JS, Marcinkiewicz J, Zhong M, Barale JC, Lazure C, Murphy RA, Chrétien M, Marcinkiewicz M: Mammalian subtilisin/kexin isozyme SKI-1: a widely expressed proprotein convertase with a unique cleavage specificity and cellular localization. Proc Natl Acad Sci U S A 1999, 96:1321-1326.

8. Day R, Schafer MK, Watson SJ, Chrétien M, Seidah NG: Distribution and regulation of the prohormone convertases PC1 and PC2 in the rat pituitary. Mol Endocrinol 1992, 6:485-497.

9. Gyamera-Acheampong C, Mbikay M: Proprotein convertase subtilisin/ kexin type 4 in mammalian fertility: a review. Hum Reprod Update 2009, 15:237-247.

10. Seidah NG, Benjannet S, Wickham L, Marcinkiewicz J, Jasmin SB, Stifani S, Basak A, Prat A, Chretien M: The secretory proprotein convertase neural apoptosis-regulated convertase 1(NARC-1): liver regeneration and neuronal differentiation. Proc Natl Acad Sci USA 2003, 100:928-933.

11. Bae JA, Park HJ, Seo YM, Roh J, Hsueh AJ, Chun SY: Hormonal regulation of proprotein convertase subtilisin/kexin type 5 expression during ovarian follicle development in the rat. Mol Cell Endocrinol 2008, 289:29-37.

12. Antenos M, Lei L, Xu M, Malipatil A, Kiesewetter S, Woodruff TK: Role of PCSK5 expression in mouse ovarian follicle development: identification of the inhibin $a-$ and $\beta$-subunits as candidate substrates. PLoS One 2011 6:e17348.

13. Diaz FJ, Sugiura K, Eppig JJ: Regulation of Pcsk6 expression during the preantral to antral follicle transition in mice: opposing roles of FSH and oocytes. Biol Reprod 2008, 78:176-183.

14. Mujoomdar ML, Hogan LM, Parlow AF, Nachtigal MW: Pcsk6 mutant mice exhibit progressive loss of ovarian function, altered gene expression, and formation of ovarian pathology. Reproduction 2011, 141:343-355.

15. Akiyama I, Yoshino O, Osuga Y, Shi J, Hirota Y, Hirata T, Harada M, Koga K, Fujimoto A, Yano T, Taketani Y: The localization and regulation of proprotein convertase subtilisin/kexin (PCSK) 6 in human ovary. Am J Reprod Immunol 2012, 68:491-498.

16. Kelty BP, Curry TE Jr: Ovarian furin (proprotein convertase subtilisin/kexin type3): expression, localization, and potential role in ovulation in the rat. Biol Reprod 2010, 83:147-154

17. Yang X, Wang Q, Gao Z, Zhou Z, Peng S, Chang WL, Lin HY, Zhang W, Wang H: Proprotein convertase furin regulates apoptosis and proliferation of granulosa cells in the rat ovary. PLOS One 2013, 8:e50479,

18. Dai G, Smeekens SP, Steiner DF, McMurtry JP, Kwok SCM: Characterization of multiple prohormone convertase $\mathrm{PC} 1 / 3$ transcripts in porcine ovary. Biochim Biophys Acta 1995, 1264:1-6.

19. Renegar RH, Owens CR, Dai G, McMurtry JP, Kwok SCM: Expression and localization of prohormone convertase $1 / 3$ (SPC3) in porcine ovary. Mol Reprod Dev 2000, 57:361-365. 
20. Vu A, Green CB, Roby KF, Soares MJ, Fei DT, Chen AB, Kwok SCM: Recombinant porcine prorelaxin produced in Chinese hamster ovary cells is biologically active. Life Sci 1993, 52:1055-1061.

21. Zarreh-Hoshyari-Khah R, Bartsch O, Einspanier A, Pohnke Y, Ivell R: Bioactivity of recombinant prorelaxin from the marmoset monkey. Regul Pept 2001, 97:139-146.

22. Neumann JL, Lazaris A, Huang YJ, Karatzas C, Ryan PL, Bagnell CA: Production and characterization of recombinant equine prorelaxin. Domest Anim Endocrinol 2006, 31:173-185.

23. Hudson P, John M, Crawford R, Haralambidis J, Scanlon D, Gorman J, Tregear G, Shine J, Niall H: Relaxin gene expression in human ovaries and the predicted structure of a human preprorelaxin by analysis of CDNA clones. EMBO J 1984, 3:2333-2339.

24. Crawford RJ, Hammond VE, Roche PJ, Johnston PD, Tregear GW: Structure of rhesus monkey relaxin predicted by analysis of the single-copy rhesus monkey relaxin gene. J Mol Endocrinol 1989, 3:169-174.

25. Evans BA, Fu P, Tregear GW: Characterization of two relaxin genes in the chimpanzee. J Endocrinol 1994, 140:385-392.

26. Sherwood OD, Key RH, Tarbell MK, Downing SJ: Dynamic changes of multiple forms of serum immunoactive relaxin during pregnancy in the rat. Endocrinol 1984, 114:806-813.

27. Soloff MS, Shaw AR, Gentry LE, Marquardt H, Vasilenko P: Demonstration of relaxin precursors in pregnant rat ovaries with antisera against bacterially expressed rat prorelaxin. Endocrinol 1992, 130:1844-1851.

28. Li M, Mbikay M, Arimura A: Pituitary adenylate cyclase-activating polypeptide precursor is processed solely by prohormone convertase 4 in the gonads. Endocrinol 2000, 141:3723-3730.

doi:10.1186/1757-2215-6-91

Cite this article as: Kwok et al: Relative expression of proprotein convertases in rat ovaries during pregnancy. Journal of Ovarian Research 2013 6:91.

\section{Submit your next manuscript to BioMed Central and take full advantage of:}

- Convenient online submission

- Thorough peer review

- No space constraints or color figure charges

- Immediate publication on acceptance

- Inclusion in PubMed, CAS, Scopus and Google Scholar

- Research which is freely available for redistribution 